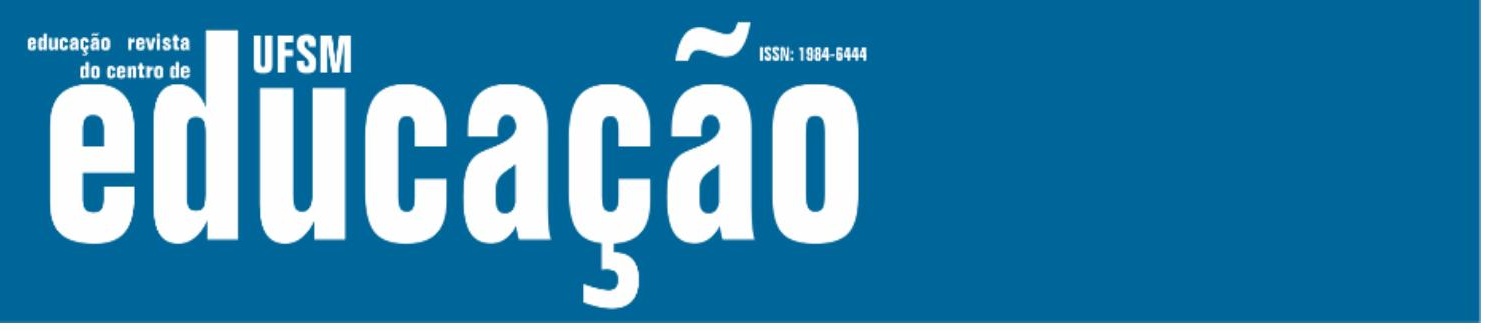

ISSN: 1984-6444 | http://dx.doi.org/10.5902/1984644443454

\title{
Prolegômenos de uma Teoria Enunciativa da Educação Popular
}

\author{
Prolegomena of an Enunciative Theory of Popular Education
}

Marcos Angelus Miranda de Alcantara

Professor doutor na Universidade Federal da Paraíba. João Pessoa, Paraíba, Brasil.

marcos84angelus@gmail.com - http://orcid.org/0000-0003-0276-3397

Erenildo João Carlos

Professor doutor na Universidade Federal da Paraíba. João Pessoa, Paraíba, Brasil. erenildojc@gmail.com - http://orcid.org/0000-0001-7272-2748

Recebido em 09 de abril de 2020

Aprovado em 20 de maio de 2021

Publicado em 04 de novembro de 2021

\section{RESUMO}

A Educação Popular (EP) é uma pedagogia que aparece na teia social da América Latina. Do ponto de vista da experiência histórica, seus princípios sustentam os trabalhos de base nos anos 1960 e 1970, conforme Freire (1987), Brandão (2006) e Carrillo (2013) afirmam. Este escrito compartilha alguns resultados da tese de doutoramento Elementos para uma Teoria Enunciativa da Educação Popular. Seu objetivo geral consiste em introduzir elementos sígnicos para formulação de uma teoria enunciativa da EP. No plano teórico/metodológico a análise toma por base algumas das ideias de Michel Foucault (2008) e está centrada nos elementos constitutivos em um conjunto de enunciados da EP. Dessa análise resulta a ideia de que o discurso atravessa a camada linguística e sócio-histórica desses enunciados. Verifica-se que o discurso analisado produz modos de falar, de articular e de escrever sobre EP, identificáveis mediante uma série de signos, vinculados à EP. Os resultados apontam, portanto, que o discurso da EP na América Latina se assenta em uma série de princípios éticos, políticos e epistemológicos que lhe conferem um modo de existência particular.

Palavras-chave: Educação Popular; Análise Arqueológica do Discurso; Teoria Enunciativa.

\section{ABSTRACT}

Popular Education (PE) is a pedagogy that appears on the social web of Latin America. From the point of view of historical experience, its principles underpin the grassroots work in the 1960s and 1970s, as Freire (1987), Brandão (2006) and Carrillo (2013) state. This paper shares some results of the doctoral thesis Elements 


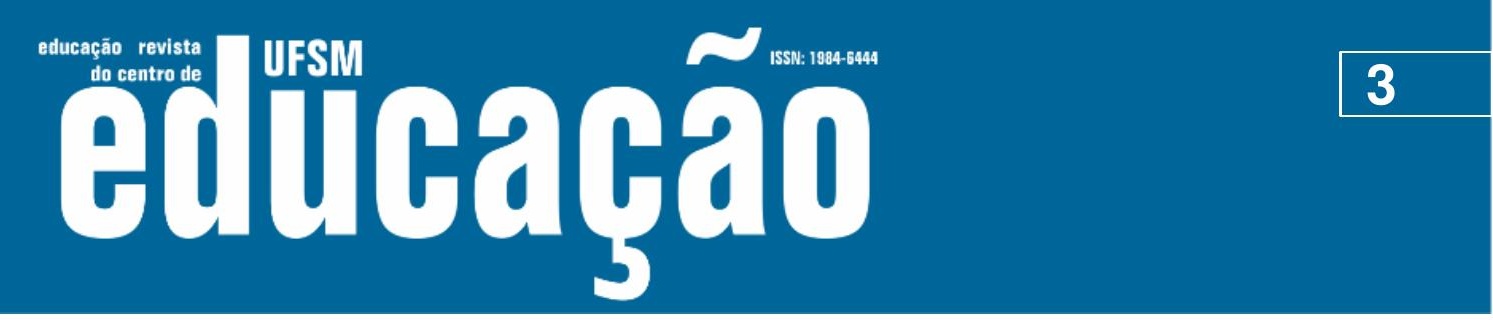

ISSN: 1984-6444 | http://dx.doi.org/10.5902/1984644443454

brasileiro, conceitualmente, pode ser definida como uma pedagogia "[...] a partir da qual os coletivos sociais leem e se relacionam com a realidade e na qual as subjetividades são primordiais" (CARRILLO, 2013, p. 15). Para contribuir com essa construção teórica precisamos ampliar o debate corrente além do pensamento marxiano ou fenomenológico. Daí, a proposta deste escrito de introdução a uma teoria enunciativa da Educação Popular.

Esta pesquisa tomou como pressuposto a existência de uma relação entre a Educação Popular e linguagem. Isto implica dizer que sua dimensão discursiva é o centro da preocupação. Inspirada nos estudos arqueológicos foucaultianos, ganha centralidade nesta análise a dimensão enunciativa do discurso. Não se trata de negar a dimensão histórica, pedagógica e política da Educação Popular, mas de tomar por objeto a sua dimensão enunciativa, a partir dos campos de domínio que permitem a coexistência dos signos enunciativos educação e popular.

Nesta perspectiva, aqui são apresentados alguns resultados relativos à tese de doutoramento Elementos para uma Teoria enunciativa da Educação Popular. Trata-se de uma pesquisa que buscou identificar o contributo da Análise Arqueológica do Discurso ao campo investigativo desta pedagogia. Sua especificidade incide precisamente em um olhar particularizado à dimensão do enunciado. Em suma, o texto discorre sobre o modo como os signos enunciativos estão dispostos e atravessa as camadas linguísticas e sócio-histórica do discurso que constitui modos de se falar sobre Educação Popular. Portanto, o objetivo geral deste escrito consiste em introduzir elementos sígnicos para formulação de uma teoria enunciativa da educação popular.

\section{A Análise Arqueológica do Discurso como abordagem teórico- metodológica para escavação dos signos enunciativos da Educação Popular}

Michel Foucault (2008), em sua arqueologia, utiliza essa ideia de função para definir a noção de enunciado e apresenta as seguintes características da função enunciativa: 1) impossibilidade de uma descrição formal, semântica ou lógica; 2) 


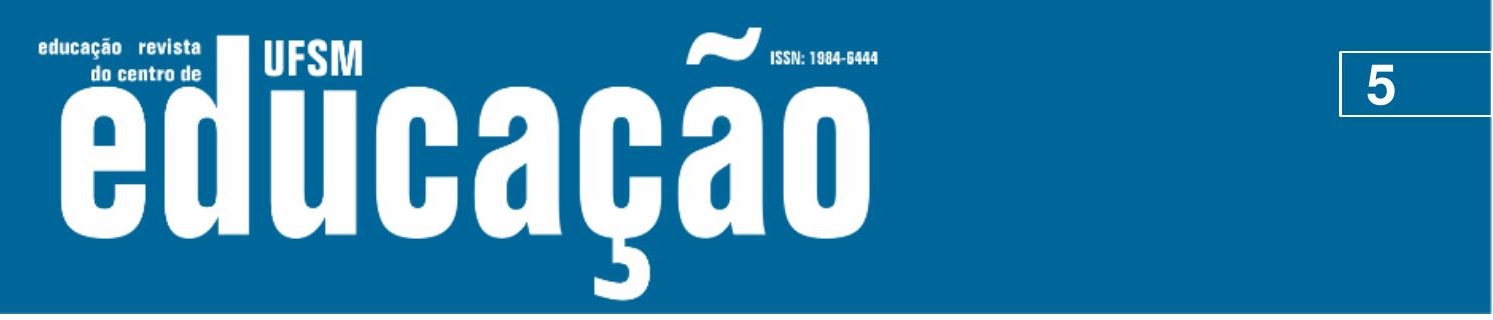

ISSN: 1984-6444 | http://dx.doi.org/10.5902/1984644443454

acontecimento, neste caso, do aparecimento de um enunciado em certa ordem discursiva.

Do ponto de vista procedimental da análise, não importa, por exemplo, a quantidade de vezes que determinada frase, imagem, expressão, palavra-chave ou ideia apareça em determinado documento consultado. O enunciado não terá uma maior ou menor regularidade por causa de sua repetição. $O$ aparecimento frequente não é causa, no máximo, podemos dizer que se trata de um efeito. Nessa perspectiva, "renunciaremos, pois, a ver no discurso um fenômeno de expressão - a tradução verbal de uma síntese realizada em algum outro lugar; nele buscaremos antes um campo de regularidade [...]", conforme assevera Foucault (2008, p. 61).

\section{Significados, significantes e referentes como camadas constitutivas dos signos enunciativos da Educação Popular}

Mediante a formulação da tese de que a Análise Arqueológica do Discurso pode contribuir com elementos para a constituição de uma teoria enunciativa da Educação Popular foi preciso um processo arqueológico de análise discursiva do enunciado, que, por definição, é uma série de signos aos quais podemos atribuir "[...] modalidade de existência própria [...]" (FOUCAULT, 2008, p. 121). Essa particularidade que permite a existência enunciativa do signo não se dá como estrutura nem como partícula atômica, mas como função.

Escavar o enunciado, pressupõe percorrer a série sígnica Educação Popular. Isso implica identificar os significantes (marcas empíricas, gráficas, sonoras, pictóricas, nesse caso específico, a palavra escrita e falada), os significados (as ideias mobilizadas mediante o significante) e os referentes (objetos concretos que a relação significado/significante aciona) (SAUSSURE, 2006), (PEIRCE, 2008), (FREGE, 2010) e (SANTAELLA, 2012). 


\section{Aillbapẫ

ISSN: 1984-6444 | http://dx.doi.org/10.5902/1984644443454

profissionais, quando atuam nos espaços regulados institucionalmente, operam um movimento que retroalimenta o acontecimento da educação, seja nos espaços institucionais ou não. Isso evidencia a complexidade desse acontecimento social, histórico e concreto desse referente.

O signo educação tem uma complexidade evidenciada por essa incursão em sua tricotomia. Por meio desse movimento, constatamos que o significante, a partir de sua etimologia latina, já aparece como condição de possibilidade de articular seu significado nas noções de levar, de conduzir e de trazer o educando para o lado de fora, seja de seu mundo subjetivo, seja da caverna de Platão. O significado da educação estaria nessa ideia de redirecionar o olhar para o real e distinguir sua reprodução, suas sombras e seus ecos. A esse duplo, agrega-se o referente, que produz e posiciona sujeitos concretos. O referente está além da abstração, porquanto está presente na história, na política, na economia, nas instituições, em suma, na vida.

\section{O signo enunciativo popular}

$\mathrm{Na}$ etimologia, originária do significante popular, deparamo-nos com a expressão latina populus, que também está conectada a alguns outros significantes: povo, povoado, povoamento, povoar, população, popularidade etc. Enfim, grande parte das palavras latinas que originam as línguas modernas e contemporâneas português, francês, espanhol, italiano etc. - relacionadas ao signo popular trazem em seu significante, total ou parcialmente, a origem em populus. Isso implica dizer que, em sua gênese, esse significante está vinculado à noção de povo. Tal articulação ocorre com base na ideia de população, de comunidade, enfim, de gente, pessoas ou de determinado coletivo que tem algo em comum, que compartilha certo território, algum traço étnico, aspecto histórico, linguístico, cultural, social, entre outros.

As características amplas desse significante - ou vagas - favorecem as condições de emergência de um amplo significado para o signo popular. Ou poderíamos falar em significados? No senso comum, encontramos significados que, se, de um lado, restringem as ideias de o que é popular, de outro, apresentam-se de 


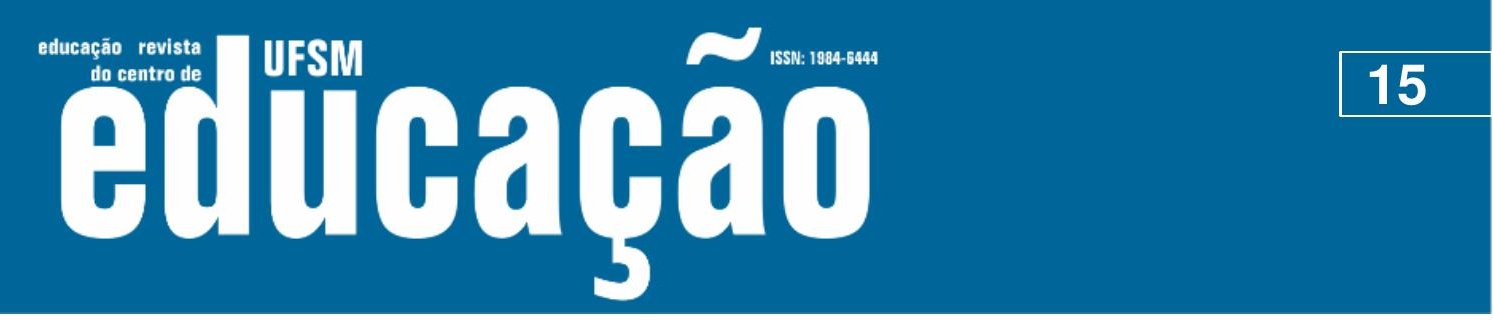

ISSN: 1984-6444 | http://dx.doi.org/10.5902/1984644443454

subversão, da resistência e da luta contra alguma forma de opressão. Freire (1987), ao discutir sobre as relações entre opressão e liberdade, define o termo popular como a condição de sujeito oprimido. Em Manfredi (1980 apud MELO NETO, 2003), significa uma prática, uma espécie de saber/instrumento que direciona para determinada luta política e o exercício da cidadania, uma classe social e um agir coletivo (WANDERLEY, 1980; BEZERRA, 1980; BRANDÃO, 1980; BEISIEGEL, 1992 citados por MELO NETO, 2003). Em suma, trata-se de um significado que aciona ideias como:

[...] o segmento social dinâmico, aberto e também conflitivo, sendo, portanto, histórico e dialético, enquanto que se dinamiza e se atualizada de forma permanente [...] Algo é popular se tem origem nos esforços, no trabalhado do povo. [...] Mas a origem apenas não basta. Essa, inclusive, pode nascer de agentes externos, evitando-se, contudo, todo tipo de populismo que porventura possa surgir. Todavia, é preciso ter-se conhecimento da direção em que está apontando o algo que se postula popular. É preciso saber quem está sendo beneficiado com aquele tipo de ação. Algo é popular se tem origem nas postulações dos setores sociais majoritários da sociedade ou de setores comprometidos com suas lutas, exigindo-se que as medidas a serem tomadas beneficiem essas maiorias. [...] Ser popular, portanto, significa estar relacionando as lutas políticas com a construção da hegemonia da classe trabalhadora (maiorias), mantendo o seu constituinte permanente, que é a contestação. É estar se externando através da resistência às políticas de opressão e adicionadas com políticas de afirmação social. Uma ação é popular quando é capaz de contribuir para a construção de direção política dos setores sociais que estão à margem do fazer político (MELO NETO, 2003, p. 10-17).

O primeiro elemento constitutivo do significado que Melo Neto (2003) traz é a origem. Algo é popular se tem origem popular. À primeira vista, esse é um axioma lógico e óbvio. Todavia, considerando que determinadas ações podem ser de interesse popular, (do povo), mas, não necessariamente, ter origem no povo, é possível a seguinte dedução lógica: tudo o que se origina do povo é popular, mas nem tudo o que é popular se originou do povo. O terceiro elemento agregado a esse significado é o conhecimento da direção que essa ação está tomando. Partindo ou não do povo, para uma ação ser popular, ela deve beneficiá-lo. O significado que Melo Neto (2003) apresenta, grosso modo, considera que, independentemente da origem da ação, ela será popular se atender conscientemente aos verdadeiros interesses do povo, não somente em suas finalidades, mas também em seus meios. 


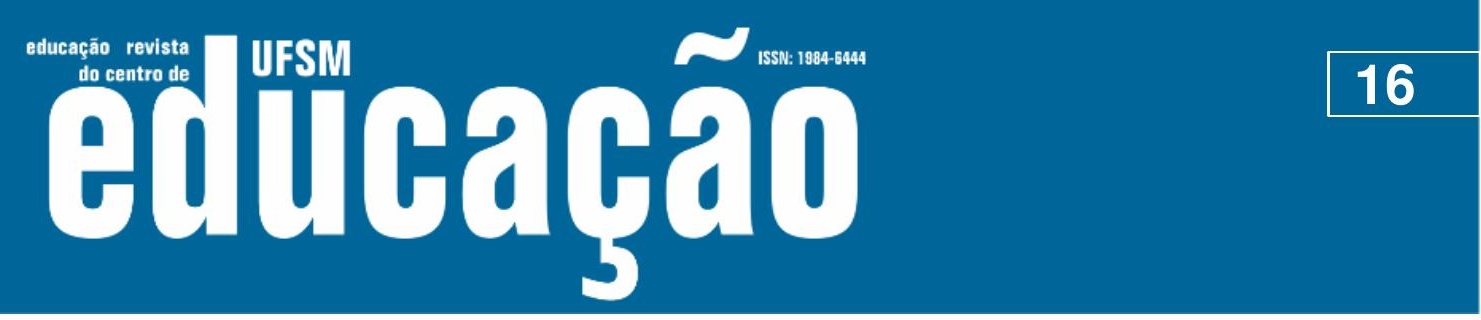

ISSN: 1984-6444 | http://dx.doi.org/10.5902/1984644443454

Convém deixar claro que estamos falando do signo popular (CANCLINI, 2004). Em outras palavras, assim como o signo educação tem uma dimensão histórica, concreta, com efeitos reais na vida das pessoas, constituindo subjetividades e, ao mesmo tempo, inserido dialeticamente na macroestrutura, o signo 'popular' também tem sua dimensão referencial, portanto, não é pura abstração, está situado no tempo e no espaço. Ao recorrer ao poeta Hesíodo, Melo Neto (2003) apresenta algumas referências, desde a Antiguidade, a trabalhadores camponeses. Também menciona a própria organização grega de Estado, fundada em valores marcados pelo princípio do direto para todos, que alicerçavam a polis na cidadania grega e, ao mesmo tempo, organizava a vivência comunitária.

Ainda na Antiguidade, exemplificamos, junto com Melo Neto (2003) e Cambi (1999), alguns episódios narrados na Bíblia, que se configuram como um referente do signo popular. Trata-se do povo judeu, praticante do Judaísmo. Segundo a tradição bíblica, é um povo originário da Tribo de Judá, uma das doze tribos de Israel (aquele que luta com Deus, em sua etimologia hebraica). Israel foi o nome dado pelo deus dos hebreus a Jacó, um dos patriarcas do povo de Israel ou da nação israelita. Historicamente, todavia, esse povo semita/hebreu/israelita ou designado pelo nome de uma de suas tribos, ou genericamente judeus, tem uma trajetória de luta e resistência contra a opressão de impérios antigos. Em suma, esse povo se constituiu de

[...] populações nômades que viviam do pastoreio, ligadas a uma religião totalmente diversa daquela dos vizinhos e contemporâneos, monoteísta e que concebe Deus como espírito absolutamente transcendente, não representável e não nominável (é apenas "aquele que é"); um Deus que fez, porém, um pacto com seu povo (Israel), ao qual revelou sua gênese ao mundo e as tábuas da lei e que o assiste na sua história, que é de sofrimentos impostos por Deus para pôr à prova seu próprio povo, mas também de espera: de um Libertador, de um Messias, de um guia que fará Israel triunfar sobre todos os seus inimigos (CAMBI, 1999, p. 69).

Se o episódio do Êxodo, com as pragas lançadas pelo deus hebreu ao grande Egito, e o cajado milagroso de Moisés, que conduzia o povo para a abertura do Mar Vermelho, tudo narrado cinematograficamente na Torá e no Pentateuco (os cinco primeiros livros da Bíblia), são fantasiosos e literários, admitamos, ao menos, que 


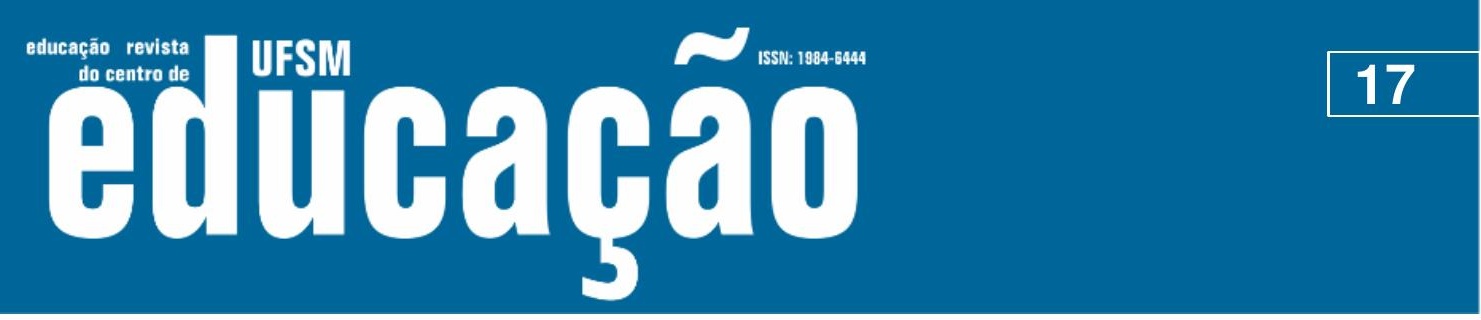

ISSN: 1984-6444 | http://dx.doi.org/10.5902/1984644443454

sejam metafóricos. Até a parte referente aos quatro séculos de escravidão no Egito carece de registros historiográficos suficientes. Contudo, pelo menos, toda essa narrativa (embora pobre de referências e rica de significados) serviria de inspiração política para que esse povo conservasse suas tradições, seus saberes, suas práticas religiosas, enfim, seu anseio por liberdade e outras formas de resistência ao período de cativeiro na Babilônia (600 AC) sofrido pelo antigo Reino de Judá, para que suportasse a invasão romana liderada pelo General Pompeu (63 $A C$ ) à cidade de Jerusalém e a destruição do Templo de Jerusalém (70 DC) pelo General Tito. Esses são fatos que constam da historiografia e constituem concretamente um modo de ser popular do povo de Israel, que lutou, seja com seu próprio deus, metaforicamente falando, seja contra invasões e exílios registrados pela historiografia na Antiguidade.

$\mathrm{Na}$ Idade Média, alguns movimentos de contestação ao poder da Igreja (HOORNAERT, 1986) também constituem o referente do signo popular. Como esse é um período marcado pelo domínio do clero em todos os setores - político, econômico, social e cultural - essa instituição detinha o poder de vida e de morte sobre as pessoas, e sobre o destino dos que morriam, emitia salvo conduto para expiar seus pecados e garantir sua entrada no paraíso - as indulgências. Ela se colocava como o único caminho que poderia levar a deus: fora da lgreja não há salvação. Em outras palavras, quem não seguia suas doutrinas, seus dogmas ou não compartilhava dos seus valores, sofreria determinadas consequências, em todos os sentidos, não apenas espiritual, mas político, social e econômico.

É nesse contexto sócio-histórico em que "[...] se afirmava cada vez mais central o problema da liberdade" (CAMBI, 1999, p. 144), que se configurou como mais um ambiente propício à afirmação do popular como forma de resistência que fazia contraponto a todo esse poder. Calado (1999, apud MELO NETO 2003, p. 7) refere-se à "[...] indignação diante da ordem religiosa vigente [...] movimentos compostos de gente simples, das classes populares [...]" marcados pelo elemento da subversão ou desobediência civil à ordem estabelecida.

Caminhando, um pouco mais, no curso da história a fim de entender a rede que tece a dimensão referente ao signo enunciativo popular, deparamo-nos com a 


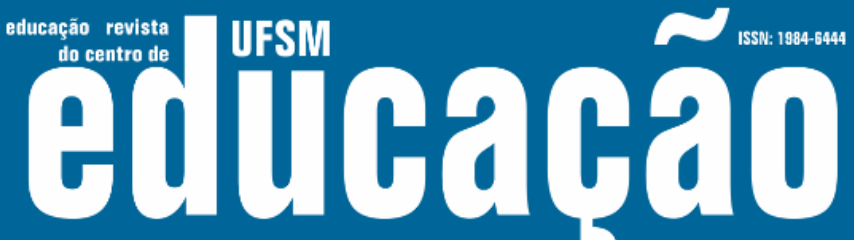

ISSN: 1984-6444 | http://dx.doi.org/10.5902/1984644443454

marca a ascensão da classe burguesa. De revolucionária a burguesia passa a ser conservadora de uma nova ordem social emergente, o capitalismo. Isso gesta as condições de emergência de novas referências para o popular, o proletariado.

Aquele espectro que ronda a Europa, no Século XIX, anunciado por Marx e Engels (2008) e denominado de comunismo, configura-se como mais uma expressão do referente popular: a classe trabalhadora, seja da nascente indústria, seja do campo. Enfim, o proletariado, que começa a se organizar de maneira sistemática, contrapõe-se à ordem burguesa estabelecida desde o final da Revolução Francesa. Os trabalhadores se distinguem da burguesia como classe social, através de sua relação estabelecida historicamente com os meios de produção.

Enquanto a burguesia reproduz uma relação de propriedade, o proletariado vende sua força de trabalho para sobreviver. Assim, a burguesia acumula, cada vez mais, capital, favorecendo condições de geração e apropriação da mais valia, o que resulta no acúmulo de mais capital. Concretamente, isso gera condições opressivas de vida para a classe trabalhadora que, ao se organizar como categoria, empreenda várias lutas por melhores condições de trabalho, de salários e de vida. No Manifesto do Partido Comunista, de 1848, Marx e Engels mobilizam, entre várias coisas, um discurso político sobre esse movimento popular e sugerem que essa luta deve acontecer no âmbito internacional.

Apesar de ser inegável que essas lutas populares classificadas como socialistas tenham inspirado muitas outras formas de resistência à opressão, na Europa, na África e na América Latina, temos movimentos populares ocorridos em nosso continente que são anteriores, ainda no Século XVIII e concomitantemente ao comunismo do Século XIX e do XX. Vivemos períodos de intensos conflitos, em maior parte de nossa América, por causa da colonização espanhola ou portuguesa e dos efeitos nocivos que o capitalismo gera ao seu redor. Mesmo antes que o capitalismo aqui chegue, seja instalado e se estabeleça de vez, já há movimentos classificados como revoltas, motins e insurreições.

No Brasil, esses movimentos ocorrem de norte a sul, com movimentos religiosos messiânicos, separatistas e conspiracionistas. No Século XX, esses 


\section{Aithoapẫ \\ (3)}

ISSN: 1984-6444 | http://dx.doi.org/10.5902/1984644443454

movimentos continuam - o cangaço, no Nordeste; a Revolta da Vacina, no Rio de Janeiro, ou os influenciados pelo Marxismo, pelo Anarquismo e pela Revolução Russa de 1917: temos a Coluna Prestes, a criação do Partido Comunista etc. No final do Século $X X$, os movimentos se diversificam, outros tipos de atores sociais ganham visibilidade e pautas diferenciadas emergem: gênero, etnia, sexualidade, geração, cultura entre outros (GOHN, 2007). O fato é que todos esses e outros movimentos ocorridos na América Latina que podem mobilizar e propor situações de enfrentamento às mais variadas formas de opressão são referentes para 0 signo popular.

Portanto, esse signo se constitui, tricotomicamente, partindo de seu significante, com origem em populus, isto é, palavra latina que correlaciona todas as noções de gente e coletividade e que articula vários significados, na dimensão do senso comum, na dimensão política e na acadêmica. O terceiro vértice desse signo, o referente, está na história, nas práticas sociais de resistência a toda e qualquer forma de opressão. Pode ser identificada desde a Antiguidade até os dias de hoje. Enfim, o referente do signo popular é um coletivo de gente, que se rebela, que luta e que resiste a qualquer situação que tende negar a condição humana.

\section{Considerações finais}

Analisamos a série signos enunciativos da educação popular, não com o intuito de averiguar ou determinar conceitos preexistentes, mas para explicitar o modo como suas partes constitutivas - significante, significado e referente - estão dispostas e interagem no campo da linguagem. Diferentemente de um conceito que restringe a categoria a um campo determinado, o signo apresenta uma configuração diferente. Suas partes constitutivas não funcionam como elementos delimitadores, mas como pontos articuladores que permitem adentrar a ordem do discurso existente, porque aciona o próprio discurso por meio de domínios diversos, de regras constituintes e de posicionamentos de sujeitos. 


\section{-

ISSN: 1984-6444 | http://dx.doi.org/10.5902/1984644443454

A dimensão significante da série de signos analisada permite centrar a análise no que Foucault (2008) chamou de positividades, campos de domínio, regularidades, correlatos, funções enunciativas e posições de sujeitos. Não é o referente nem o significado, porque é o significante que, devido ao seu caráter livre das regras já aceitas convencionalmente, que estabelece correlações diversas e modos particulares de existência do signo. Devido à ruptura que o significante pode estabelecer com os significados e com os referentes, que fazem aparecer o enunciado e um campo de possibilidades analíticas, adentramos às condições de existência do enunciado da Educação Popular.

Em outras palavras, só é possível articular, traçar ou formular qualquer sentença correlata à Educação Popular por causa da anterioridade dos signos enunciativos. Ele aciona campos de domínio que associam saberes diversos: linguísticos, filosóficos, historiográficos etc. Desse modo concluímos que a análise empreendida demarca o território arqueológico do enunciado da Educação Popular.

Nos escritos foucaultianos, ao menos de modo disperso, a categoria discurso é caracterizada pela noção de objetividade. Isso foi evidenciado no decorrer da análise. Essa existência objetiva independe da individualidade dos educadores, dos educandos, das pessoas que integram os movimentos sociais populares, de pesquisadores e de qualquer outro ente envolvido com essa prática educativa. Embora esses discursos sejam produzidos socialmente e não estejam relacionados somente às experiências, mas também, sobretudo, a outros discursos presentes em outros espaços e tempos históricos diversos, não podemos perder de vista sua dimensão produtiva dessas e de outras práticas.

Isto implica dizer que essa enunciabilidade da Educação Popular, a um só tempo é produzida e produz as lutas dos movimentos, as experiências educativas, em suma, os processos históricos. Embora uma coisa seja correlacionada a outra, sua coexistência também conserva uma relativa autonomia. $O$ fato é que a existência concreta da Educação Popular já está posta nas experiências educativas, na história, nas práticas sociais, enfim, nas lutas para superar as condições sócio-históricas e culturais que determinam a desigualdade ou qualquer outra forma de opressão.

Pretendemos com essa investigação contribuir com 0 processo de transição/ampliação teórico/conceitual da Educação Popular que ocorre na América Latina, ao menos nas últimas três décadas. Isto aparece tanto do ponto de vista do entendimento 


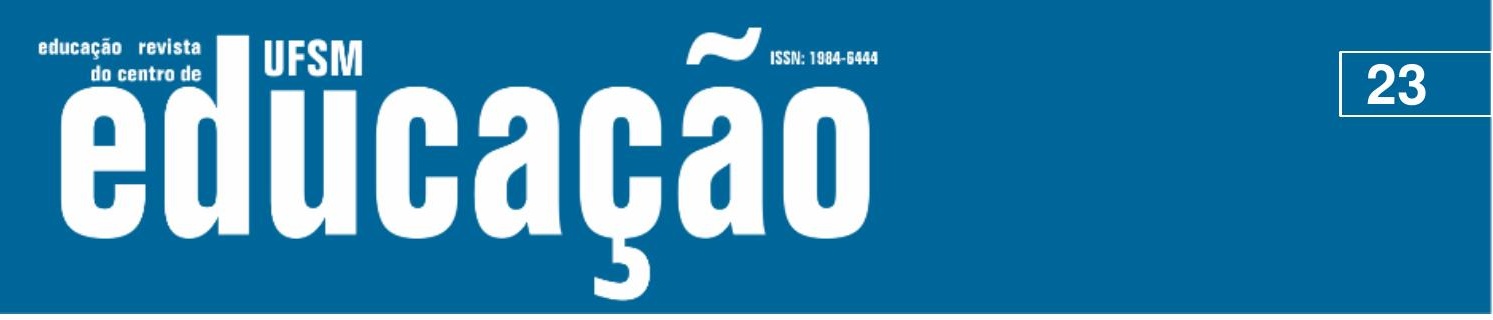

ISSN: 1984-6444 | http://dx.doi.org/10.5902/1984644443454

CAMBI, Franco. História da Pedagogia. Tradução: Álvaro Lorencini. São Paulo: Fundação Editora da UNESP (FEU), 1999.

CANCLINI, Néstor García. De qué estamos hablando cuando hablamos de lo popular? Diálogos en la acción, primera etapa. 2004. p. 153-165. Disponível em: http://www.perio.unlp.edu.ar/catedras/system/files/garcia_canclini_-

_de_que_estamos_hablando_cuando_hablamos_de_lo_popular.pōff. Acesso em: 13 mar. $201 \overline{6}$.

CARRILLO, Afonso Torres. A Educação Popular como prática política e pedagógica emancipadora. In: STREK, Danilo R.; ESTEBAN, Maria Teresa (Orgs.). Educação Popular: lugar de construção social e coletiva. Petrópolis/RJ: Vozes, 2013. p. 15-32.

FOUCAULT, Michel. Arqueologia do Saber. Tradução: Luiz Felipe Beata Neves, 7. ed. Rio de Janeiro: Forense Universitária, 2008.

FREGE, Gottlob. Lógica e filosofia da linguagem. 2. ed. ampl. e rev. São Paulo: EDUSP, 2010.

FREIRE, Paulo. Pedagogia do oprimido. 17. ed. Rio de Janeiro: Paz e Terra, 1987 (Digitalizado).

GOHN, Maria da Glória. Movimentos Sociais, Políticas Públicas e Educação. In: JEZINE, Edneide; ALMEIDA, Maria de Lourdes Pinto de (Orgs.). Educação e Movimentos Sociais: novos olhares. Campinas/SP: Alínea, 2007.

HOORNAERT, Eduardo. A memória do povo cristão. Petrópolis: Editora Vozes, 1986.

MARX, K.; ENGELS, F. Manifesto do partido comunista. São Paulo: 1. ed. 72p. (Expressão Popular) 2008.

MELO NETO, José Francisco de. O que é popular?. In: BRENNAND, Edna Gusmão de Góes. O labirinto da educação popular. João Pessoa: Editora Universitária UFPB, 2003. p. 33-57.

MORIN, Tania Machado. Práticas e representações das mulheres na Revolução Francesa - 1789-1795. 2009. Dissertação (Mestrado em História Social) Faculdade de Filosofia, Letras e Ciências Humanas, Universidade de São Paulo, São Paulo, 2009. Disponível em: http://www.teses.usp.br/teses/disponiveis/8/8138/tde-01022010-165929/. Acesso em: 20 mar. 2016.

PEIRCE, Charles Sanders; COELHO NETO, José Teixeira. Semiótica. 4. ed. São Paulo: Perspectiva, 2008. 


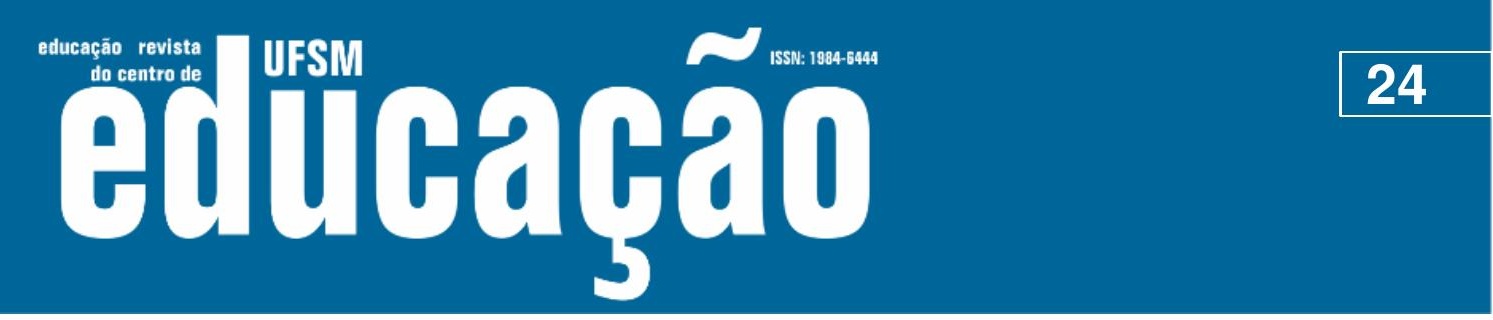

ISSN: 1984-6444 | http://dx.doi.org/10.5902/1984644443454

PINTO, Álvaro Vieira. A evolução do conhecimento. Os caracteres do conhecimento científico. In: Ciência e existência: problemas filosóficos da pesquisa científica. 2. ed. Rio de Janeiro: Paz e Terra, 1979. p. 11-60.

PLATÃO. A República. Tradução: Enrico Corvisieri. São Paulo: Nova Cultural Ltda, 1997. (Digitalizado). 352p. Disponível em: http://www.portalfil.ufsc.br/republica.pdf. Acesso em: 22 dez. 2016.

ROUSSEAU, Jean-Jaques. Emílio ou Da Educação. Tradução: Sérgio Milliet. 3. ed. Rio de Janeiro: Bertrand Brasil, 1995. 592p. (Digitalizado).

SAES, Laurent Azevedo Marques de. Morin, Tania Machado. Virtuosas e perigosas: as mulheres na Revolução Francesa. São Paulo: Alameda, 2013, 370 P. Rev. Hist. (São Paulo), São Paulo, n. 171, p. 461-468, Dec. 2014. Disponível em http://www.scielo.br/scielo.php?script=sci_arttext\&pid=S0034-

$83092014000200461 \&$ Ing=en\&nrm=iso . Acesso em: 20 mar. 2016.

SANTAELLA, Lúcia. O que é semiótica. São Paulo: Brasiliense, 2012. 131 p. (Coleção Primeiros Passos 103)

SAUSSURE, Ferdinand de. Curso de Linguística Geral. 27. ed. São Paulo: Cultrix, 2006.

SAVIANI, Dermeval. Escola e democracia: teorias da educação, curvatura da vara, onze teses sobre educação e política. 32. ed. Campinas/SP: Autores Associados, 1999.

UNESCO. La educación de personas jóvenes y adultas em América Latina y el Caribe: Prioridades de acción en el siglo XXI. CEAAL-CREFAL-INEA Santiago de Chile, Mayo 2000.2 Disponível em http://unesdoc.unesco.org/images/0012/001214/121482so.pdf . Acesso: 17 dez. 2014.

VOVELLE, Michel. A Revolução Francesa e seu eco. In: Estudos Avançados, 1987. p. 25-45. Disponível em: http://www.scielo.br/pdf/ea/v3n6/v3n6a03.pdf. Acesso: 12 ago. 2017.

WANDERLEY, L. E. Educação popular e processo de democratização. In. BRANDÃO, Carlos Rodrigues. (Org.). A questão política da educação popular. 2. ed. São Paulo: Brasiliense, 1980.

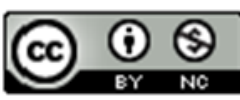

This work is licensed under a Creative Commons Attribution-NonCommercial 4.0 International (CC BY-NC 4.0) 